\title{
Filmes de Prédio: Espaço, Arquitetura e Heterotopia em Filmes ${ }^{1}$ Building Movies: Space, Architecture and Heterotopia in Films
}

\section{Maria Helena Braga e Vaz da Costa}

\footnotetext{
${ }^{1}$ A definição "filmes de prédio" não é de minha autoria. A ouvi em uma conversa informal com a professora Ângela Prysthon, da UFPE, que não lembrava de quem tinha ouvido essa definição sobre os filmes pernambucanos. Contudo, Portugal e Migliorin (2018) fazem referência ao recorrente interesse, do cinema brasileiro contemporâneo, pela temática urbana centrada no processo de verticalização das cidades e no impacto da especulação imobiliária, e ao termo "filmes de prédio" como sendo "informalmente" cunhado. Para uma análise da produção fílmica brasileira da atualidade no contexto da representação do espaço urbano, ver Portugal (2016).

2 Pós-doutora em Cinema pelo International Institute - University of California at Los Angeles (UCLA) - USA; doutora e mestra em Estudos de Mídia pela University of Sussex - Inglaterra; graduada em Arquitetura e Urbanismo pela Universidade Federal de Pernambuco (UFPE). Bolsista de Produtividade em Pesquisa do CNPq; professora titular do Departamento de Artes da Universidade Federal do Rio Grande do Norte (UFRN); Atua como pesquisadora na área de Cinema no contexto dos seguintes temas: estudos sobre a imagem fílmica e o espaço; olhares imagéticos sobre a cidade, a arquitetura e o espaço urbano; cultura visual; culturas moderna e pós-modernidade. Contato: mhcosta.ufrn@gmail.com
} 
Resumo: Este artigo propõe investigar as particularidades das representações do espaço urbano e da paisagem arquitetônica da cidade do Recife nos filmes Deserto feliz (2008), de Paulo Caldas, Um lugar ao sol (2009), de Gabriel Mascaro, e Aquarius (2016), de Kleber Mendonça Filho. Discute-se aqui sobre como essas representações servem como estruturas que delineiam a imaginação geográfica sobre o espaço e a paisagem recifense, atribuindo significado à experiência de vivência do lugar e à correlação existente entre as paisagens real e fílmica da cidade, contextualizadas em uma ordem socioespacial que se institui como heterotópica.

Palavras-chave: filmes pernambucanos; espaço; arquitetura; heterotopia.

Abstract: This article investigated the particularities of representations of the urban space and the architectural landscape of the city of Recife in the films Deserto feliz (2008) by Paulo Caldas, Um lugar ao sol (2009) by Gabriel Mascaro and Aquarius (2016) by Kleber Mendonça Filho, analyzing how these representations serve as structures that delineate the geographical imagination of the Recife space and landscape, giving meaning to the experience of living there, and to the existing correlation between the real and filmic landscapes of the city contextualized in a socio-spatial order that is defined as heterotopic.

Keywords: Pernambuco films; space; architecture; heterotopia. 


\section{Apresentação e problematização}

Notadamente, a forte presença de imagens fílmicas no imaginário coletivo em várias culturas tem provocado efeitos que reverberam nos mecanismos de produção de espaços e paisagens urbanas, e, certamente, tem influenciado no estabelecimento de uma cultura geográfica pautada nas imagens em movimento dos espaços e dos lugares representados nos filmes.

Indubitavelmente, na atualidade, filmes têm, cada vez mais, se tornado objeto empírico de interesse para os mais diversos campos do conhecimento comunicação, geografia, arquitetura, estudos urbanos, estudos culturais, entre outros. Comum a esses campos é o interesse pela pesquisa com a intenção de ampliar a compreensão sobre conceitos de espaço e de paisagem, o que se constata pelo volume de publicações envolvendo a análise fílmica como método para pesquisas de cunho interdisciplinar nas mais diversas áreas do conhecimento (AZEVEDO, 2006; BARNES; DUNCAN, 1992; BESSE, 2006; COSTA, 2009; FERRAZ, 2006; MARANDOLA; HOLZER; OLIVEIRA, 2014; MASSEY, 2008, entre muitos outros).

Há algum tempo, arquitetos e geógrafos humanistas e culturais vêm chamando a atenção sobre a força simbólica dos edifícios e traçados urbanos que compõem a paisagem das cidades. Pyrs Gruffudd (2014), por exemplo, inicia o seu artigo Building sites: cultural geographies of architecture and place-making defendendo exatamente esse postulado. Nesse contexto, destaca-se a contribuição de Michael Foucault acerca da construção de uma geografia em que o espaço não é um vazio a ser preenchido por pessoas e coisas, mas um conjunto de relações sociais que definem, na contemporaneidade, localizações que se sobrepõem, se entrelaçam e geram heterotopias.

Interpretar a paisagem (real e/ou fílmica), "ler" os edifícios e os elementos urbanos que a compõem, constrói a problematização considerada por Domosh (1989) como determinante dos vínculos entre um artefato particular de determinada paisagem, seu contexto socioeconômico-estético e os atores que diretamente produzem e criam esse artefato. Essa prática "interpretativa” da paisagem, que Lees (2001) denomina “semiótica política", deve considerar a maneira pela qual a paisagem é construída e moldada, adquirindo significado a partir das atividades que a produzem, apropriam e habitam, e também avaliá-la numa perspectiva cultural (LEES, 2001).

Práticas sociais e culturais singularizam espaços, lugares e edifícios que compõem o espaço urbano tanto quanto impõem, à visualidade sígnica da paisagem, simbolismos diretamente associados a elas. Essas mesmas práticas, por sua vez, 
influenciam a produção arquitetônica e da arte coletiva, tendo os seres humanos, pensantes e ativos, como transformadores e criadores, intermediados pela comunicação. Com efeito, tornam-se produções simbólicas, códigos de comunicação para os quais concorrem o sensório e o imagético, que servem à interpretação do real já que, dialeticamente, engendram-no e, por vezes, recriam-no.

Nessa concepção, a cultura, produtora e ao mesmo tempo produto do espaço construído, tem a dimensão do político - além do econômico e do social - como uma esfera importante de poder, que dá direção e significado às coisas. Da mesma forma, a paisagem urbana também pode inferir contestação política, mas igualmente ser um instrumento de resolução de conflitos sociais, promovendo assim aquilo que os seus controladores desejam.

Sabemos que as cidades (o tópos, o lugar) são modificadas em suas representações (fotográficas, pictóricas, fílmicas etc.). Contudo, constatamos que há sempre a possibilidade de estabelecimento de uma relação entre a cidade real e sua representação. Como bem expõe Sarlo (2014): “As imagens de cidade propuseram-se representações de diversas ordens: alegórica, simbólica, realista, de costumes, irônica. Mas a cidade construída estava por baixo dessas representações, mesmo das imaginárias 'cidades perfeitas"” (SARLO, 2014, p. 204-205).

Na mesma linha de Sarlo (2014), gostaria de defender o argumento de que algumas representações fílmicas de cidades, em sua relação com a materialidade do espaço urbano real, terminam por operar como "forças materiais que exercem pressão sobre a imaginação urbana” (SARLO, 2014, p. 206). As imagens fílmicas, contextualizadas na sua relação real/ficcional, simultaneamente, ajudam os sujeitos a se autodefinirem e a situar essas definições em relação à sua própria experiência real e subjetiva do espaço. Afinal, essas mesmas imagens fílmicas compõem, por sua vez, parte do processo de conhecimento e idealização espacial. Isso é exatamente o que sucede com muitos dos filmes pernambucanos contemporâneos que apresentam diversas concepções de paisagem urbana para compor construções heterotópicas do lugar.

Em acordo, Mitchell (1994) escreve que a fotografia de paisagem é uma representação de algo que é em si mesmo uma representação. Antes dessa representação secundária, contudo, a paisagem é um meio físico e multissensorial no qual significados e valores culturais são codificados, sejam eles colocados lá pela transformação física do lugar em uma paisagem jardim ou arquitetura, ou encontrada em um lugar formado pela natureza. Como Mitchell (1994, p. 14) advoga, paisagem, em si mesma, “já é um artifício no momento de sua contemplação”. Com essa distinção entre o que chamamos de vista ou imagem, é possível teorizar 
que as pessoas só podem perceber a terra como paisagem transformando-a em vista/ imagem/panorama.

No que se refere à representação fílmica, mise-en-scène é o termo francês utilizado para se referir ao que está posto em cena - modificações no espaço ou no arranjo dos objetos e performers em cena. Refere-se também a qualquer item dentro do plano visual da câmera que amplia a visão de que o lugar no filme não é estável ontologicamente. Há sempre uma tensão dinâmica entre lugar e espaço no filme, em que a narrativa transforma continuamente lugar em espaço, e vice-versa, da ação e do drama. Na mesma direção, encontramos narrativas visuais que obsessivamente se repetem, naturalizando significados hegemônicos como parte de um determinado status quo, o que colabora com a noção de heterotopia discutida adiante.

As produções cinematográficas nos ajudam a compreender o movimento e as experiências no espaço, nos lugares e paisagens naturais ou construídas. Por meio do processo de interpretação dos filmes que ambientam sua narrativa em espaços e lugares diversos, suas relações sociais, políticas, econômicas e culturais, nos é permitido acesso iluminador à realidade, e também às subjetividades que permeiam e moldam não somente sua aparência, mas também o imaginário coletivo que se constitui a partir dela. Ademais, fica claro que não necessariamente precisamos nos concentrar no entendimento dos espaços e lugares reais, mas antes nestes como ideia.

Em acordo, este artigo é resultado da investigação sobre a participação das imagens fílmicas na constituição de uma cultura geográfica a partir da multiplicidade imagética e espacial das paisagens urbanas. Aqui, a paisagem urbana é explorada enquanto sujeito e objeto autônomo das subjetividades espaciais inerentes à cultura. Para isso, nos ocupamos da análise de alguns filmes contemporâneos, dirigidos por cineastas pernambucanos, para compreendermos os seus discursos sobre o espaço e a paisagem construídos a partir da realidade objetiva.

Compreendendo que "os conflitos vivenciados pelos personagens são indissociáveis dos espaços que habitam e por onde (não) circulam” (AZERÊDO, 2020, p. 266), o objetivo aqui é discutir como diferentes imagens da cidade do Recife, capital do estado de Pernambuco, em sua configuração urbana e arquitetônica, são tematizadas como estruturas que delineiam a imaginação geográfica sobre o espaço e a paisagem e dão sentido e significado à experiência de vivência do lugar. Nesses filmes, as imagens da cidade não são trabalhadas para servir de cenário às narrativas, mas para serem tema.

Os cineastas pernambucanos contemporâneos, inseridos no âmbito do que se costuma nominar como o período da pós-retomada do cinema brasileiro, têm se 
destacado nacional e internacionalmente por um trabalho que vem motivando novos olhares sobre os espaços e lugares geográficos e urbanos. Discutir sobre a diversidade da representação do espaço e da paisagem arquitetônica no contexto cinematográfico, produzido especialmente por cineastas pernambucanos, significa oportunizar a discussão sobre a representação fílmica do Recife. Dessa forma, contribuirá para situarmos e entendermos o aparecimento de distintas e variadas formas de olhar a paisagem urbana e arquitetônica mais particularmente.

A intenção é também refletir sobre a correlação existente entre o espaço urbano, a arquitetura e a paisagem real e fílmica do Recife e a importância dessa relação para o entendimento de uma ordem socioespacial que se institui como heterotópica. Isso é, este trabalho propõe uma análise, pautada sob uma perspectiva interdisciplinar e crítica, a partir do real, do fílmico e do simbólico contidos na premissa de heterotopia, e na intersecção dos espaços sociais que se interconectam no espaço urbano recifense. A análise se debruça sobre as representações das paisagens espaciais e arquitetônicas construídas nos filmes Deserto feliz (2008), de Paulo Caldas, Um lugar ao sol (2009), de Gabriel Mascaro, e Aquarius (2016), de Kleber Mendonça Filho.

\section{Cinema, cidade e paisagem}

Nacional e internacionalmente, o cinema produzido em Pernambuco contemporaneamente remete a uma determinada série de filmes dirigidos por um grupo de cineastas pernambucanos - Lírio Ferreira, Cláudio Assis, Marcelo Gomes, Hilton Lacerda, Paulo Caldas, Kleber Mendonça, Marcelo Pedroso, Gabriel Mascaro, Marcelo Lordello. Reconhecidos pela diversidade temática e pelo processo colaborativo 3 que caracterizam seus trabalhos como arrojados e importantes para o contexto da produção nacional, proporcionam uma alternativa à centralidade do “eixo Rio-São Paulo" no que toca à expansão da produção de filmes no Brasil.

Revisitando lugares e destacando configurações urbanas da cidade do Recife, essa geração recente de filmes produzidos em Pernambuco tem demonstrado criatividade artística, comprometimento político e social e capacidade de informar e afetar localmente e nacionalmente as audiências. A escolha deliberada por filmar em locação segue a noção de que um lugar real afeta significantemente a maneira como o filme é apreendido pela audiência, já que o "reconhecimento" espacial e do lugar é acionado.

\footnotetext{
${ }_{3}^{3}$ Há de se destacar, como uma particularidade da produção cinematográfica pernambucana, o processo de colaboração e parceria existente entre os cineastas, operando e consolidando vínculos de camaradagem no compartilhamento do trabalho - produção, financiamento coletivo, novos conceitos de distribuição -, denominado "brodagem".
} 
Atuando como um mapa do imaginário e das realidades do cotidiano sociocultural e geopolítico recifense, esses filmes recorrem ao espaço como categoria narrativa para apresentarem a cidade do Recife sob um olhar que configura sua paisagem urbana sob o foco da relação passado-presente e a contextualiza no âmbito de dicotomias como tradição-modernidade, centro-periferia, ordem-desordem, nos âmbitos social, político e econômico do lugar.

Os cineastas Paulo Caldas, Gabriel Mascaro e Kleber Mendonça Filho, por exemplo, preocupados com a renovação da dramaturgia fílmica nacional, utilizam os espaços urbanos e sua arquitetura como paisagem simbólica em seus filmes, traçando um mapeamento geográfico fílmico em que a cidade não é cenário, a cidade é tema. Seus filmes cartografam as temáticas sociais, políticas, econômicas e urbanas impressas na paisagem, tais como: especulação imobiliária e o acelerado processo de verticalização das cidades, segregação e violência socioespaciais, formas de resistência política e econômica, conflitos de classe e dramas sociais e a desumanização resultante do não ordenamento responsável das cidades.

Portanto, significados sociais e culturais são não apenas construídos, mas discutidos, entrelaçados e contestados por meio das paisagens urbanas contidas nos filmes desses cineastas, que debatem, no centro de suas narrativas, as construções ideológicas e identitárias, crenças e valores. Por tudo isso, entendemos que algumas das obras de Paulo Caldas (Deserto feliz, O rap do pequeno príncipe contra as almas sebosas), Gabriel Mascaro (Doméstica, Av. Brasília formosa, Um lugar ao sol) e Kleber Mendonça (Recife frio, O som ao redor, Aquarius) compartilham a "crítica ao modelo de cidade excludente e calcada no medo" (SILVA; MELLO, 2019, p. 105), modelo de organização do espaço que, presume-se, a cidade do Recife tem seguido.

Múltipla, híbrida e repleta de contrastes, Recife se revela, por meio de imagens, sons e movimento nos filmes pernambucanos, uma cidade que afirma sua heterogeneidade. Quem sabe, na diversidade das "Recifes" fílmicas que são construídas a partir desse cinema, a cidade nos aparece como, parafraseando Nogueira (2014), uma cidade que se mostra com a vocação para ser o que não é. Destaca-se, nesses casos, uma “ousadia estética” que nos faz lembrar aquilo a que Jacques Aumont (2008) se refere como uma tendência do cinema mundial que se instaura a partir dos anos 1980: uma "supradramaturgia”, que se constrói a partir do experimentalismo formal conseguido por meio do uso abusivo da lente grande angular (olho de peixe), do cinemascope, do apelo dramático por meio da edição de som e do uso das cores e da textura da imagem, trabalhada em enquadramentos insólitos. 
Focando no signo da espacialidade urbana e da desigualdade social, assim como na sua realidade espacial e no contraste com os diferentes signos da cidade, o interesse aqui recai sobre os filmes que constroem o espaço fílmico por meio de imagens de lugares existentes na realidade. Ou seja, naqueles em que os cineastas se valem de locações na cidade recifense como espaços privilegiados para as suas narrativas, na intenção de que esses lugares sirvam como enunciados estruturais que contribuam para a impressão de realidade.

Assim, os filmes discutidos aqui são aqueles que se apropriam do espaço urbano e da paisagem do Recife para criar uma geografia fílmica heterotópica repleta de diferenciadas formas, sons, cores, paisagens, espacialidades, climas, personagens etc. Essesfilmes recorremàtemática da metrópole “desolada” esemafetode Desertofeliz(2007); a um Recife assoberbado pela desenfreada especulação imobiliária e pelo processo de verticalização que transforma sua paisagem social e arquitetônica em Aquarius (2016) e Um lugar ao sol (2009).

Destaque é dado aqui às estruturas narrativas que promovem um diálogo com espaços e lugares existentes no Recife para construir simbolismos a partir da própria referência à realidade da cidade - um composto de fragmentos de vistas, vivências e lembranças que, apesar de compor narrativas ficcionais, tem base no que se sabe, e se imagina, sobre o lugar. Além disso, mesmo que a cidade real e a cidade fílmica não se sobreponham, se anulem ou mesmo intercambiem seus elementos, devido a diferentes ordens semióticas, quando confrontamos a cidade fílmica com a cidade real, entendemos e reconhecemos o que significam os desvios entre uma e outra (SARLO, 2014). A cidade em que houve intervenção por meio de uma representação fílmica transforma a realidade ficcional em experiência real - o que nos faz lembrar Foucault:

O espaço no qual vivemos, que nos leva para fora de nós mesmos, no qual a erosão das nossas vidas, do nosso tempo e da nossa história se processa num contínuo, o espaço que nos mói, é também, em si próprio, um espaço heterogêneo. Por outras palavras, não vivemos numa espécie de vácuo, no qual se colocam indivíduos e coisas, num vácuo que pode ser preenchido por vários tons de luz. Vivemos, sim, numa série de relações que delineiam sítios decididamente irredutíveis uns aos outros e que não se podem sobre-impor. (FOUCAULT, 1986, p. 3)

\section{Heterotopia e os "filmes de prédio"}

Quando nos referimos ao conceito de "heterotopia" pensamos diretamente em Michael Foucault, para quem a heterotopia caracteriza a justaposição, em um 
só lugar real, de múltiplos espaços (locais) que são em si mesmos inconciliáveis. Foucault (1986), usando o espelho como uma metáfora, concebe a noção de que o espelho funciona como heterotopia:

O espelho funciona como uma heterotopia neste momentum: transforma este lugar, o que ocupo no momento em que me vejo no espelho, num espaço a um só tempo absolutamente real, associado a todo o espaço que o circunda, e absolutamente irreal, uma vez que para nos apercebermos desse espaço real, tem de se atravessar esse ponto virtual que está do lado de lá. (FOUCAULT, 1986, p. 3)

A partir dessa revelação sobre o "reflexo" da realidade espacial no espelho, Foucault percebe que não existem limites entre o que é realidade e o que é ilusório no espaço social. O conceito de heterotopia pode explicar, por exemplo, a confluência entre os diferentes espaços na sociedade e como as relações neles alicerçadas definem as relações sociais dos indivíduos. A noção de heterotopia, assim, nos permite pensar a realidade do espaço social através da ideia de representação (reflexo) dos lugares que abrigam as relações na sociedade.

Outro exemplo citado por Foucault para elaborar uma concepção fundamental de heterotopia é o navio. Produtor de imaginários e espacialidades, o navio “é a heterotopia por excelência. Em civilizações sem barcos, esgotam-se os sonhos, e a aventura é substituída pela espionagem, os piratas pela polícia” (1986, p. 7). O navio, assim, é o lugar das experiências individuais e coletivas, é o transporte para a terra paradisíaca que permeia o imaginário popular. $\mathrm{O}$ que nos faz lembrar a ideia de "ilha" (isolamento, proteção), mencionada por um dos entrevistados em Um lugar ao sol que se utiliza da imagem da ilha para definir o espaço da cobertura como perfeito ao propiciar elevação e distância das pessoas que transitam no nível da rua “da cobertura você tem uma outra dimensão: é o por cima” (UM lugar ao sol, 2009).

Entendemos que a configuração heterotópica no documentário Um lugar ao sol contextualiza diferentes dimensões espaciais em sua estrutura. O espaço do apartamento de cobertura, realização de um sonho individual, materializa-se como experiência do morar luxuoso e do privilégio social; em outro plano (elevado), que denota a sensação de domínio do espaço, configura o cenário paisagístico como construção de ficções de felicidade que o próprio aparato cinematográfico empreendeu no imaginário dos espectadores - “é uma cena viva de cinema”, diz um dos entrevistados sobre a "vista privilegiada" que tem da sua janela. 
Em vista do exposto, a possibilidade de pensar o espaço e a paisagem fílmicos como heterotopia faz sentido. O próprio Foucault faz referência à sala de projeção e à experiência cinematográfica como heterotópicas: “assim é o que acontece no cinema, essa divisão retangular tão peculiar, no fundo da qual, num écran bidimensional se podem ver projeções de espaços tridimensionais" (FOUCAULT, 1986, p. 5). A partir disso, nos é permitido avançar com a ideia de que filme pode ser dialeticamente o espelho que produz o espaço virtual no qual eu "volto a mim mesmo", como atesta Foucault.

No caso do filme, a noção do "espelho" - como projeção ilusória que encapsula o reflexo e a projeção de duas realidades em um mesmo espaço e tempo (KRUGER, 2016) - funciona pelo processo de identificação do espectador com personagens, situações, paisagens, espaços e lugares narrativos, e pela união entre um espaço irreal (a cidade no filme) e um espaço real (a cidade per si). Ora, se para Foucault a noção de heterotopia concerne a expressão da junção de dois lugares, o real e o irreal, postos no mesmo espaço simbólico, e constatamos que o aparato cinematográfico trabalha exatamente com essa ideia, podemos afirmar que os filmes trazem para a realidade uma experiência heterotópica - apesar de que o fator "tempo" não trabalha da mesma forma, pois não existe a "simultaneidade" na temporalidade da imagem como há no caso do espelho. "Com a ideia de heterotopia, não existem limites entre o que é a realidade e o que é ilusório no espaço social" (KRUGER, 2016, p. 36).

Como possibilidade alternativa para compreender a dimensão representacional do espaço social e como ele abriga e aproxima diferentes lugares que constituem o sujeito social e cultural, podemos considerar o que Foucault descreve como heterotopia de crise $^{4}$ : lugares que contêm indivíduos em estado de crise em determinada sociedade. Foucault exemplifica com as experiências sexuais, fora de suas residências, de mulheres em lugares “designados" para encontros de natureza sexual. A noção de heterotopia de crise, identificada e discutida no âmbito da análise dos filmes de interesse nesse trabalho, amplia a percepção do espaço real e sobre o conceito de lugar em diversos espectros.

Em acordo, reconhecemos em Deserto feliz (2008), de Paulo Caldas, filme que tem como tema a prostituição infantil, o abuso sexual e o universo feminino em sua dimensão social, tratados de maneira dura e seca através de uma "poética do tempo real" (PASSAGES, 2019), uma heterotopia do desvio no que se refere a

\footnotetext{
${ }^{4}$ Foucault se refere também à heterotopia do desvio, que remete a lugares aos quais se destinam aqueles indivíduos considerados “desvios” em relação à média ou às normas da sociedade, como hospitais e prisões. Lugares, portanto, que abrigam os sujeitos que causam instabilidade social.
} 
uma das locações do filme e que, significativamente, representa o lugar na cidade e da ação no espaço fílmico. Me refiro ao Edifício Holiday, situado no bairro de Boa Viagem, que percebo ser apresentado no filme como "lugar do desvio" nos moldes que apregoa Foucault.

Construído em 1957, o Edifício Holiday, até 2019, abrigava cerca de 2 mil pessoas. Ícone da arquitetura modernista na cidade - imensa estrutura de concreto curvada, em forma de meia lua, com 17 andares e 476 apartamentos -, o prédio conta com pelo menos 30 estabelecimentos comerciais espalhados em seu pátio, no térreo, que servem aos moradores e à vizinhança. $\mathrm{O}$ imóvel é considerado um símbolo da expansão imobiliária na região da praia de Boa Viagem por estar no centro do território disputado pela elite econômica pernambucana.

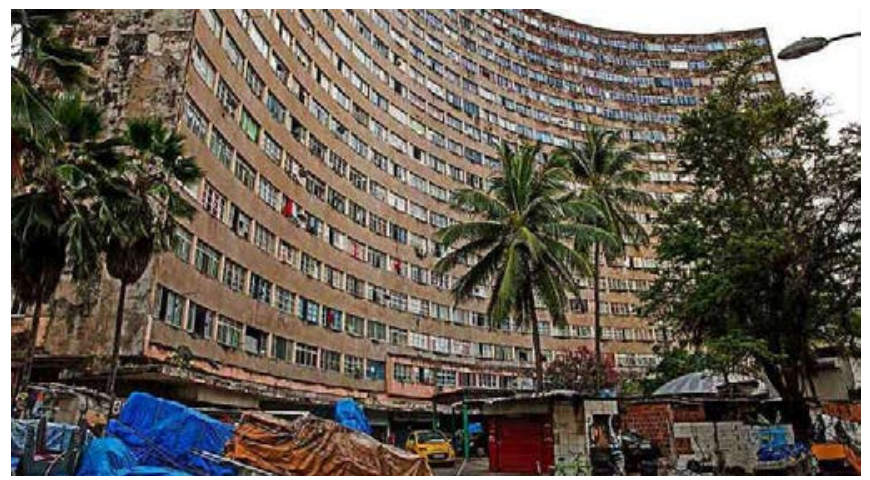

Figura 1: Edifício Holiday.

Fonte: Adolescente... (2017)

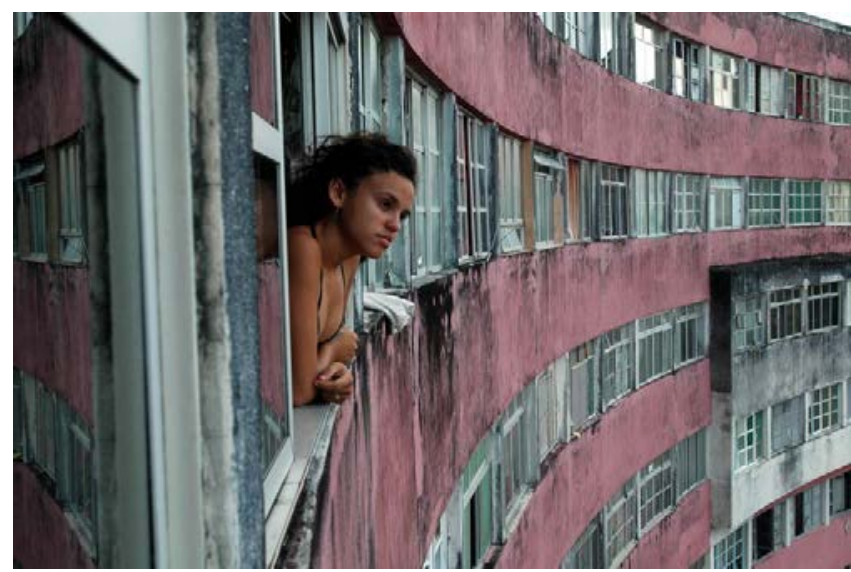

Figura 2: Personagem Jéssica (Nash Laila) no Ed. Holiday. Fonte: Deserto feliz (2008) 
Considerado há muito tempo uma "favela vertical”, a degradação do edifício é visível em sua fachada com a fiação elétrica exposta, sujeira acumulada e paredes desgastadas. Por isso mesmo, em 2019, a justiça determinou a sua desocupação e interdição, a partir da solicitação da Prefeitura do Recife, para que obras estruturais e de renovação da parte elétrica do prédio fossem realizadas. Os então habitantes do Edifício Holiday, hoje desocupado, ainda esperam pelas reformas que, pelo menos até fevereiro de 2020, ainda não tinham iniciado.

Em Deserto feliz, o Edifício Holiday significa o lócus da prostituição, mesmo contrariando a realidade factual que posiciona o prédio em contexto distinto. Na realidade, os habitantes do prédio são, sobretudo, trabalhadores das redondezas, como porteiros, ambulantes da praia, faxineiras, empregadas domésticas. Isso é, trabalhadores de baixa renda, fato que pode ser constatado nas falas dos reais moradores do prédio5. Todavia, a "má fama” do Edifício Holiday, citada por seus reais moradores, é de ser o domicílio de bandidos, traficantes e prostitutas. Desse modo, verifica-se que a realidade fílmica do lugar (o Edifício Holiday) em Deserto feliz está mais associada ao imaginário simbólico e coletivo dos recifenses sobre o prédio do que à realidade do lugar per si. Nesse caso, constatamos exatamente a fusão de duas realidades, a real e a representacional, em um mesmo espaço que atua como "reflexo" do real e do simbólico simultaneamente.

Quando Foucault diz que “a heterotopia tem o poder de justapor em um só lugar vários espaços, vários posicionamentos que são em si próprios incompatíveis" (2015, p. 435), fazendo uma analogia com o filme Deserto feliz, e retomando o exemplo do espelho citado acima, podemos estabelecer que o espaço irreal (projetado na tela) e o espaço real (representado no filme), mutuamente a realidade e a (ir)realidade, compõem o espaço social e simbólico. O próprio cineasta Paulo Caldas, em entrevista a Lucia Nagib e Samuel Paiva (PASSAGES, 2019), diz ter pretendido com o filme "romper a barreira entre a ficção e a realidade" mostrando a geografia humana do lugar. Nesse sentido, o destaque ao Edifício Holiday como lugar significativo no filme coloca a audiência em contato com a relação ficção/realidade, dando ao filme um tom de documentário por meio da especificidade arquitetônica real e simbólica existente não apenas na realidade concreta, como também na imagética - através do uso de tomadas aéreas do Edifício Holiday seguidas de tomadas no nível do solo.

\footnotetext{
${ }_{5}^{5}$ Os moradores do Edifício Holiday são entrevistados pela equipe do Diário de Pernambuco na reportagem documental "Edifício Holiday: Imponente e Melancólico", disponível em: https://bit.ly/39ea7fN. Acesso em: 19 jun. 2020.
} 
Encontramos no filme Aquarius (2019), de Kleber Mendonça Filho, de maneira mais explícita, a intenção de abordar as temáticas da especulação imobiliária, do processo de verticalização e do mal ordenamento da paisagem urbana da cidade do Recife em sua relação direta com a luta pelo direito à habitação e uma efetiva resistência de forma individual ou em comunidade ${ }^{6}$. Como evidenciado por Azerêdo, em uma das sequências iniciais de Aquarius, "ao captar o espaço geográfico da cidade em câmera alta, [o filme] também alude às transformações causadas pelo tempo e pela especulação" (AZERÊDO, 2020, p. 273). Assim, o discurso temático se constrói proporcionalmente na medida em que o espaço fílmico vai sendo delineado - através de visões panorâmicas ou abertas, enquadramentos mais específicos da rua, dos prédios e seus arredores.

O enredo de Aquarius gira em torno de Clara (Sônia Braga), viúva de 65 anos, última moradora do edifício Aquarius, no bairro do Pina, situado na orla da praia de Boa Viagem no Recife, que resiste, persistentemente, às investidas de uma construtora que almeja comprar o prédio e demoli-lo para erguer, em seu lugar, um outro edifício mais alto e mais moderno. O filme deixa muito clara sua crítica ao sistema de ideias que legitima o poder econômico da classe dominante e que torna mais fácil ceder à pressão, seguir pensamentos e atos predominantes, do que resistir aos padrões da sociedade, do mercado, dos interesses do poder.

O "Aquarius da vida real" é na verdade o Edifício Oceania (usado como locação no filme), localizado na Avenida Boa Viagem, que "pelo charme saudosista de sua arquitetura” (ARAÚJO, 2016) destoa da paisagem constituída pelos espigões modernos que compõem a orla da praia de Boa Viagem no bairro do Pina. Símbolo de resistência à especulação imobiliária, o prédio, projetado pelo engenheiroarquiteto Hugo Marques, foi construído em 1952 (cinco anos antes do Edifício Holiday) e é um dos últimos representantes de uma geração de edifícios construídos na região.

Ainda que evidentemente explícita a relação entre o título de Aquarius, o local de gravação das cenas (a locação) e a respectiva relação narrativa com os espaços, lugares e temas da realidade que poderíamos contextualizar na discussão sobre os "filmes de prédio", comentarei uma sequência do filme que alude a um outro lugar, uma outra arquitetura, um outro edifício.

Me refiro à sequência em que a personagem de Sônia Braga, Clara, em companhia do sobrinho Tomás (Pedro Queiroz), sobe de carro a Ponte Antônio de

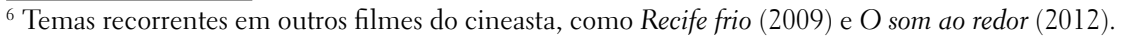


Góis, no Pina. A sequência mostra, em um plano aéreo, a Bacia do Pina, o Clube Cabanga e as redondezas. Nota-se, na sequência, que da paisagem foram excluídas as "torres gêmeas" - como são conhecidos dois edifícios gigantes símbolos do processo de verticalização da cidade, construídos pela empreiteira Moura Dubeux, beneficiados com o amparo à especulação imobiliária que há décadas vem tomando os bairros do Recife, impactando as paisagens naturais ou construídas pela história e protegidas pelo patrimônio cultural da cidade.

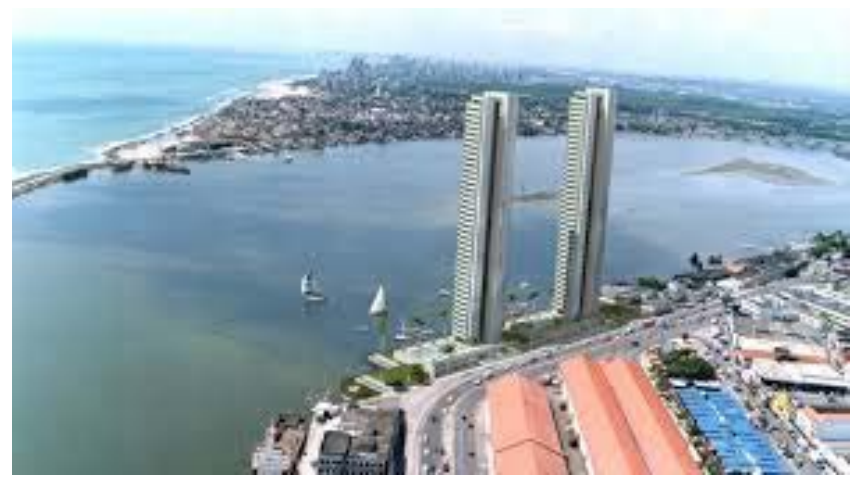

Figura 3: As "torres gêmeas" em Recife.

Fonte: BRITO, 2016

Os Edifícios Píer Duarte Coelho e Píer Maurício de Nassau, apelidados de "torres gêmeas", com 41 andares e 134 metros de altura cada um, fazem parte da paisagem às margens do Rio Capibaribe no cais de Santa Rita, Bairro de São José, região considerada patrimônio histórico do Recife. Com a exclusão digital das duas torres da paisagem histórica do Recife (Figura 4), Kleber Mendonça Filho certifica a temática intencionada no filme, qual seja: a modernização pretendida pelos poderes público e imobiliário do ambiente urbano recifense às custas da desvalorização da memória, ignorando as pessoas e suas histórias (temática presente também em Deserto feliz, mesmo que subliminarmente).

Não bastasse o efeito especial utilizado por Mendonça em Aquarius, o cineasta postou em rede social a imagem fotográfica de uma cena do filme sem as torres gêmeas acompanhada da seguinte pergunta: "O que há de correto com essa imagem de Aquarius?” (Figura 5). Claramente assumindo uma posição favorável à resistência de movimentos sociais ${ }^{7}$ que têm se colocado contrários à especulação

\footnotetext{
${ }^{7}$ Outro exemplo de resistência de movimentos sociais no Recife aconteceu em relação à construção de imenso projeto imobiliário no Cais Estelita, também no bairro de São José. Empreiteiras e poder público
} 
imobiliária desenfreada, aos interesses econômicos de empreiteiras e do poder público, à desvalorização do patrimônio histórico, social e da memória da cidade do Recife, o cineasta não se fez de rogado ao responder a críticas sobre o "apagamento" de parte da paisagem real do bairro de São José, comentando: "Foi muita tentação. O filme é meu e quem manda nele sou eu" (FERREIRA, 2016).

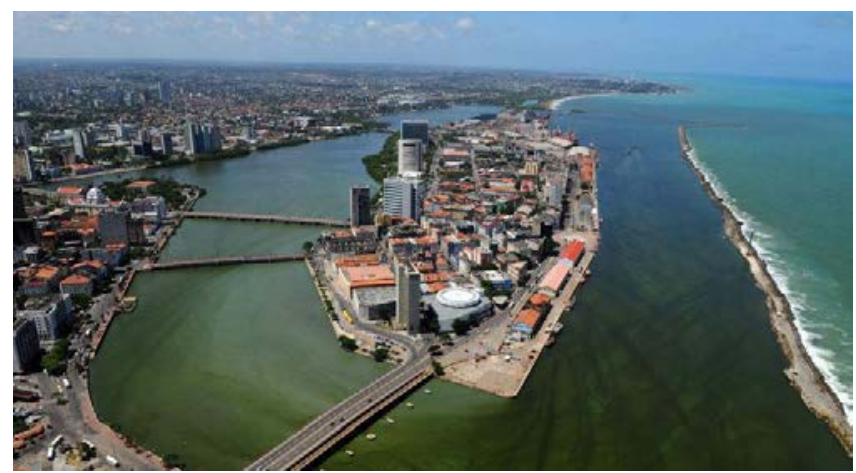

Figura 4: Cena do filme Aquarius sem as torres gêmeas. Fonte: Aquarius (2016)

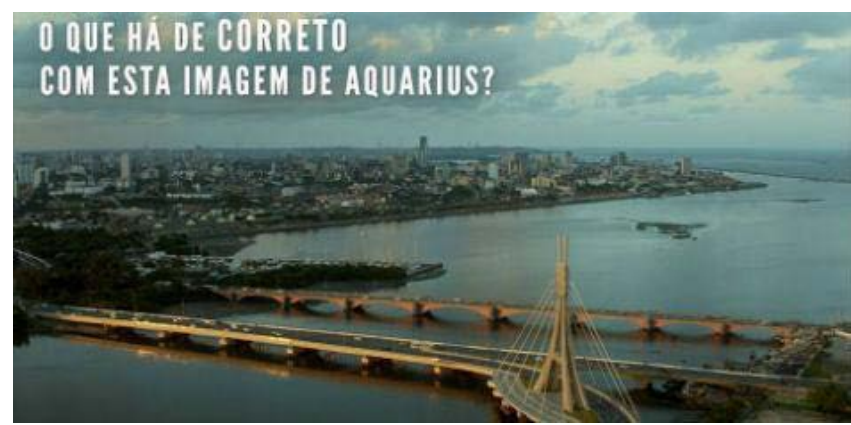

Figura 5: Imagem de Aquarius reproduzida por Kleber Mendonça Filho no Facebook. Fonte: FOTO... (2016)

Podemos pensar os filmes Deserto feliz e Aquarius como representações que são organizadas com o objetivo de, parafraseando Sarlo, se situarem entre "a realidade da cidade, a experiência de cidade e a ideia de cidade" (2014, p. 164). A mudança na paisagem do lugar explicitamente proposta no filme Aquarius é evidência das divisões existentes no contexto das relações entre as classes sociais média e alta em

se uniram em defesa do Consórcio Novo Recife em oposição à população e a grupos de direitos urbanos, que deflagraram o "Movimento Ocupe Estelita” (PADRÃO, 2015). 
suas estruturas familiares, de como essas são transgredidas e os espaços recuperados através de reconfigurações em sua arquitetura e paisagem, e da ferocidade do processo de gentrificação nas cidades brasileiras. Mendonça, entrevistado por Lúcia Nagib e Samuel Paiva (PASSAGES, 2019), afirma que "o mercado é uma das coisas mais cínicas que existem na nossa vida moderna".

Um lugar ao sol (2009), de Gabriel Mascaro, é um filme documentário que se ocupa de abordar o universo de moradores de apartamentos de coberturas de edifícios ocupados pela elite econômica nas cidades do Recife (Figura 6), Rio de Janeiro e São Paulo. O cineasta obteve acesso aos moradores das valorizadas coberturas através de um livro que mapeia a elite e as pessoas influentes no Brasil. O livro catalogou 125 apartamentos de cobertura, contudo, Mascaro só conseguiu autorização para entrevistar os moradores de nove deles. Destes, cinco são coberturas de edifícios situados à beira mar, na Avenida Boa Viagem, no Recife.

Em artigo sobre Um lugar de sol, Costa e Costa destacam que "[a] linguagem do documentário constrói seu discurso por meio da enunciação de códigos e símbolos originários nos discursos envolvidos nas relações de poder entre classes sociais" (COSTA; COSTA, 2017, p. 101). O sujeito “Outro”, no caso aquele que não faz parte da elite recifense (na verdade, da elite brasileira de uma maneira geral) e, portanto, não mora em um apartamento de cobertura, não aparece nem é entrevistado no filme. No entanto, o seu "apagamento" chama a atenção para as relações sociais e de poder envolvidas no contexto da convivência em sociedade entre as diferentes classes, principalmente porque, mesmo ausente, esse "Outro" se apresenta como um símbolo não personificado da estratificação social que se faz presente na sociedade brasileira contemporânea, e da qual o apartamento de cobertura é emblema.

No que se refere ao Recife, constatamos em Um lugar ao sol uma referência subliminar ao âmago da história da cidade no que toca a um fenômeno social muito robusto: o movimento de migração da elite canavieira pernambucana do campo para a cidade e o consequente loteamento de grande parte da área costeira, que se tornaria um dos seus bairros nobres: Boa Viagem. Como o interesse deste trabalho é discutir a paisagem urbana e arquitetônica recifense, me atenho a comentar as entrevistas dos moradores das coberturas do Recife - reconhecendo, contudo, que o discurso proposto no documentário conduz ao entendimento de que a realidade posta não é localizada ou específica, mas sim característica dos grandes centro urbanos brasileiros. 


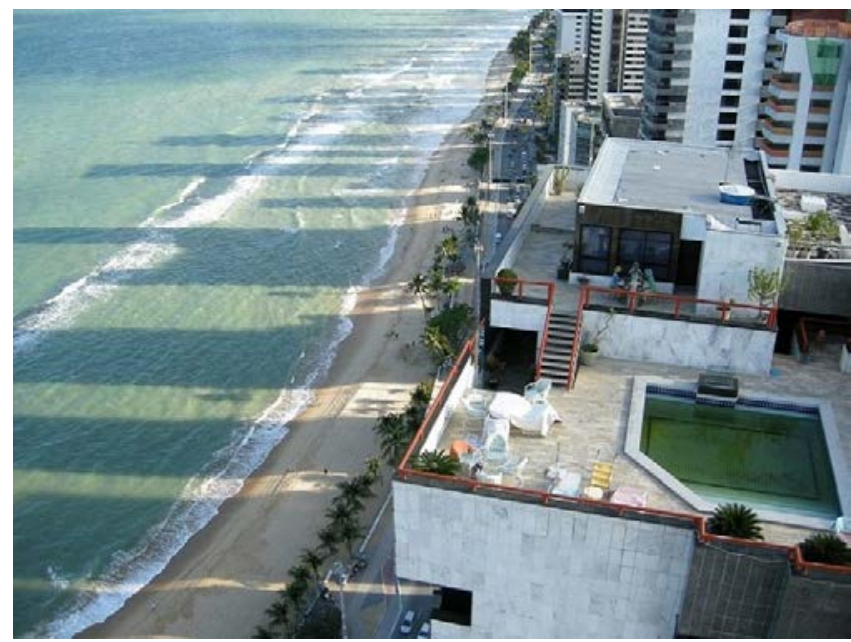

Figura 6: Imagem do filme Um lugar ao sol.

Fonte: Um lugar ao sol (2009)

Através da edição, que agrega tomadas aéreas, de detalhe de vários prédios e seus apartamentos de cobertura, suas diferentes fachadas e interiores, além dos depoimentos dos moradores dessas coberturas, o documentário apresenta uma amostra de como a elite brasileira que vive nesses apartamentos de luxo vê a si mesma. As perguntas colocadas aos entrevistados são basicamente duas: "Como é viver em uma cobertura?" e "O que, para você, significa ter uma cobertura?” O documentário traz um rico debate sobre desejo, visibilidade, segurança, status e poder, e constrói um discurso sensorial sobre o paradigma arquitetônico e social brasileiro - apresentado em categorias dicotômicas como alto/baixo; dentro/fora; convidado/intruso; segurança/ insegurança (COSTA; COSTA, 2017).

A linguagem de documentário, usada em Um lugar ao sol, insere personagens da vida real na paisagem do espaço fílmico, assegurando ao espectador o entendimento de que "aqueles personagens são reais e que os seus discursos em sua totalidade são verídicos” (NETTO, 2012, p. 102). Ademais, o filme põe em evidência aqueles sentidos que são produzidos pela intervenção da arquitetura na produção do espaço social a partir da contraposição simbólica entre: espaço interior x espaço exterior, espaço privado x espaço comum e espaço vertical x espaço horizontal (NETTO, 2012).

O documentário não deixa dúvidas sobre as motivações que levam a elite pernambucana, por exemplo, a aspirar "morar" em um apartamento de cobertura. As falas dos moradores das coberturas no Recife, situadas de frente para o mar, indicam 
desde o desejo por "mais espaço com conforto sem exagero ou luxo" e "espaço amplo para receber convidados", e ainda "uma situação geográfica que permita a vista para o mar”, até a busca por mais privacidade e segurança. Esses depoimentos caracterizam de forma paradigmática a relação do sujeito com o espaço que habita no contexto do que a tipologia do apartamento "de cobertura" expressa. Ademais, o apartamento de cobertura, apesar de não ser uma casa, tem “a cara de casa” - com jardim, piscina, vista para o mar (na maioria dos casos), espaço para animal de estimação, amplidão na distância entre as áreas social, privada e de serviço e, principalmente, afastamento do nível da rua e o que isso implica. Como destaca Rufino, "com a verticalização do ambiente, o olhar passa a ser 'superior', há o aumento das diferenças entre quem olha e o que é olhado" (2018, p. 74).

A arquitetura das coberturas apresenta uma tipologia de organograma espacial que representa o modelo de se evitar proximidade entre as diferentes classes da sociedade. Seus arranjos espaciais inferem proposições sobre o seu significado simbólico e de poder no contexto urbano na medida em que, colocando seus espaços em um "plano elevado", criam uma "sensação de domínio do espaço" para seus habitantes, que se reconhecem como privilegiados - "onde eu vivo, onde eu moro, não é a realidade do Brasil”, diz um dos entrevistados de Um lugar ao sol. Não sem razão, o "aumento vertiginoso dos prédios e de uma arquitetura e paisagem urbana que segregam e desumanizam” (AZERÊDO, 2020, p. 268) é o foco do documentário.

Retornando à ideia da cidade que se transforma pela especulação imobiliária que se apropria e toma posse de territórios, visando primeiramente o lucro financeiro, podemos identificar em Um lugar ao sol a tentativa de contrapor o discurso de uma seleta elite pernambucana à noção de preservação de uma memória sociocultural citadina, associada à preocupação com a manutenção arquitetônica, espacial e social dos lugares na cidade nordestina (COSTA; COSTA, 2017).

\section{Considerações finais}

Formulou-se neste artigo a ideia de que o filme engendra espaços heterotópicos contidos nas paisagens e territórios geográficos. Nessa perspectiva, destacamos uma abordagem acerca das heterotopias, com base na reflexão de Michel Foucault, e discutimos sobre de que modo as (re)contextualizações heterotópicas concedem novos sentidos ao espaço, ao lugar e à paisagem nos filmes de ficção pernambucanos Deserto feliz e Aquarius e no documentário Um lugar ao sol. Destacamos como esses filmes apontam para a produção de subjetividades perante o espaço e o lugar que representam, ocupam e expõem. Com efeito, constata-se 
nos filmes a presença de heterotopias de crise, reais e ficcionais, roteirizadas através das experiências correspondentes às vivências, memórias, sensações, percepções e sentimentos associados ao lugar, ao ambiente da cidade do Recife.

Os três filmes pernambucanos contemporâneos discutidos neste trabalho, de forma incisiva, expõem a vida urbana atual, reconfigurando e rearticulando novas formas de experiências, ideias, práticas espaciais e resistências. Apesar de as conexões entre arquitetura, paisagem, espaço urbano e práticas socioespaciais terem sido materializadas desde sempre, os filmes em análise rearticulam e reconfiguram as maneiras através das quais essas práticas são apresentadas, dando visibilidade a um espaço urbano específico: a cidade do Recife.

Os três filmes, direta ou indiretamente, compartilham temáticas como o espaço urbano, seu processo de verticalização e a especulação imobiliária desenfreada; a transformação da paisagem da cidade e as relações de poder entrelaçadas como causas e consequências da estratificação social; a representação das classes sociais distintas, a ideologia burguesa, a visão da elite brasileira vis-à-vis o poder econômico e o imaginário na/da paisagem arquitetônica da cidade. Derivando dessas temáticas, a questão da resistência aparece também como uma preocupação comum aos cineastas dos filmes discutidos aqui, o que demonstra uma inquietação deles sobre o juízo que se faz de uma sociedade em que determinados grupos e/ou indivíduos se contrapõem ao status quo. Há ainda que se considerar a posição solitária de cada cineasta, nos termos do que cada um deles exige de si mesmo no que se refere à “coragem” de expor seus próprios pensamentos e posicionamentos.

Por fim, este trabalho, a partir de um olhar mais aprofundado sobre filmes que tratam das relações entre as pessoas que habitam a cidade do Recife e a paisagem, percebeu o entrelaçamento de personagens e posicionamentos diversos no espaço urbano e social com a temática narrativa que dá destaque às fragilidades, conexões e conflitos reais que acontecem na cidade. Servindo, portanto, ao nosso argumento de que os filmes Deserto feliz, Aquarius e Um lugar ao sol podem ser contextualizados nas bases explicitadas por Foucault a respeito do conceito de heterotopia.

\section{Referências}

ADOLESCENTE é baleado em frente ao edifício Holiday em Boa Viagem. JC Online, Recife, 8 set. 2017. Disponível em: https://bit.ly/37czTym. Acesso em: 25 nov. 2020.

ARAÚJO, M. Verdadeiro edifício Aquarius tem sua própria Clara e assédio de construtora. UOL, Recife, 21 set. 2016. Disponível em: https://bit.ly/363kl20. Acesso em: 30 jun. 2020. 
AUMONT, J. Moderno? Por que o cinema se tornou a mais singular das artes. Campinas: Papirus, 2008.

AZERÊDO, G. "Kleber Mendonça e a ciranda de todos nós: configurações espaciais e resistência”. Significação, São Paulo, v. 47, n. 53, 2020.

AZEVEDO, A. F. "Geografia e cinema”. In: SARMENTO, J.; AZEVEDO, A.; PIMENTA, J. (orgs.). Ensaios de Geografia Cultural. Porto: Livraria Editora Figueirinhas, 2006. p. 59-79.

BARNES, T. J.; DUNCAN, J. S. (orgs.). Writing Worlds: discourse, text and metaphor in the representation of landscape. London: Routledge, 1992.

BESSE, J. M. Ver a Terra: seis ensaios sobre a paisagem e a geografia. São Paulo: Perspectiva, 2006.

BRITO, N. Blog da Noelia Brito, 2016. Disponível em: https://bit.ly/3mVCunl. Acesso em 24 junho 2020.

COSTA, M. H. B. V. "Espaços de subjetividade e transgressão nas paisagens fílmicas”. Pro-Posições, Campinas, v. 20, n. 3, 2009.

COSTA, M. H. B. V.; COSTA, W. M. A. “O outro e a arquitetura da cidade: as relações de poder em Um lugar ao sol”. Doc On-line: Revista Digital de Cinema Documentário, Covilhã, n. 21, p. 97-113, 2017.

DOMOSH, D. "A method for interpreting landscapes: a case study of the New York World Building”. Area, Ann Arbor, v. 21, n. 4, 1989.

FERRAZ, M. C. F. "Percepção e imagem na virada do século XIX ao XX". In: CORREA, A. D. (Org.). Imagem (ir)realidade: comunicação e cibermídia. Porto Alegre: Sulina, 2006. p. 233-234.

FOTO postada no Facebook de Aquarius sem as Torres Gêmeas repercute nas redes. JC Online, Recife, 4 set. 2016. Disponível em: https://bit.ly/37anhrI. Acesso em: 19 jun. 2020.

FOUCAULT, M. Ditos e escritos, vol.III - estética: literatura e pintura, música e cinema. Rio de Janeiro: Forense Universitária, 2015.

FOUCAUlT, M. “De outros espaços”. Tradução Pedro Moura. Diacritics, Baltimore, v. 16, n. 1, 1986.

GRUFFUDD, P. "Building sites: cultural geographies of architecture and placemaking”. In: OGBORN, M. et al. Cultural geography in practice. London: Routledge, 2014. p. 238-250. 
KRUGER Jr., D. A. "Foucault: a heterotopia como alternativa para pensar o espaço social”. Revista Enciclopédia de Filosofia, Pelotas, v. 5, p. 22-37, 2016.

LEES, L. "Towards a critical geography of architecture: the case of an Ersatz Colosseum”. Ecumene, Ann Arbor, v. 8, n. 1, p. 51-86, 2001.

MARANDOLA Jr., E.; HOLZER, W.; OLIVEIRA, L. (orgs.) Qual o espaço do lugar?. São Paulo: Perspectiva, 2014.

MASSEY, D. B. Pelo espaço: uma nova política da espacialidade. Rio de Janeiro: Bertrand Brasil, 2008.

FERREIRA, F. “Torres Gêmeas' de Recife foram alvos de protesto no filme Aquarius”. Folha de São Paulo, Recife, 3 dez. 2016. Disponível em: https://bit.ly/3fBOGq4. Acesso em: 21 mai. 2020.

MITCHELL, J. Picture theory: essays on verbal and visual representation. Chicago: University of Chicago Press, 1994.

NETTO, J. T. C. A construção do sentido na arquitetura. São Paulo: Perspectiva, 2012.

NOGUEIRA, A. M. C. A brodagem no cinema em Pernambuco. 2014. Tese (Doutorado em Comunicação) - Universidade Federal de Pernambuco, Recife, 2014.

PADRÃO, M. Obra em bairro histórico gera debate intenso sobre urbanização do Recife. UOL, São Paulo, l jun. 2015. Disponível em: https://bit.ly/3fGrUgX. Acesso em: 24 jun. 2020.

PORTUGAL, A. B. Geografia de espaços outros: formas de ocupar e inventar as cidades no cinema brasileiro contemporâneo. 2016. Tese (Mestrado em Comunicação) Universidade Federal Fluminense, Niterói, 2016.

PORTUGAL, A.; MIGLIORIN, C. "O infinitesimal do capitalismo contemporâneo no documentário brasileiro Banco Imobiliário”. Aniki, Lisboa, v. 5, n. 2, 2018.

RUFINO, R. H. Estética do espaço cinematográfico: uma reflexão sobre a imagem da cidade no cinema. 2018. Tese (Doutorado em Comunicação) - Universidade de Brasília, Brasília, DF, 2018.

SARLO, B. A cidade vista: mercadorias e cultura urbana. São Paulo: Martins Fontes, 2014.

SILVA, P. G.; MELLO, S. C. B. "Representações da vida cotidiana do Recife no cinema de Kleber Mendonça Filho”. Rebeca, São Paulo, v. 8, n. 2, 2019. 


\section{Referências audiovisuais}

AQUARIUS. Kleber Mendonça Filho, Brasil, 2016.

DESERTO feliz. Paulo Caldas, Brasil, 2008.

PASSAGES: a film essay. Lúcia Nagib; Samuel Paiva, Inglaterra, 2019.

UM lugar ao sol. Gabriel Mascaro, Brasil, 2009.

submetido em: 01. jul. 2020 | aprovado em: 07. out. 2020 